\title{
La dinámica del contacto linguiístico en la Amazonía ecuato-colombiana durante el siglo XVIII en textos de un misionero hablante de quichua
}

\section{Dos manuscritos de lingüística misionera en la Amazonía occidental del siglo XVIII}

En línea con el interés por la realidad de las lenguas indígenas de la Amazonía occidental, este estudio coloca en primer plano una serie de documentos históricos de reconocido interés para la lingüística misionera (Tovar 1961: 212-214; Tovar y Larrucea 1984: 230-232; Larrucea de Tovar 2012[1984]: 220). Si bien estos textos han llegado hasta la actualidad con el carácter de "anónimos", el erudito español Jiménez de la Espada (1898-1899, 1904), primer editor de uno de los manuscritos, señaló como autor muy probable al misionero franciscano Fray Fernando de Jesús Larrea y Dávalos (ca 1700-1773), quien fue ordenado sacerdote en 1725 en el convento de la Recolección de San Diego de Quito y conocido por diversas obras de evangelización en el área del Putumayo, Caquetá y Andaquíes, entre ellas la fundación de los conventos de Propaganda Fide de Quito, Popayán y Cali (Zawadzky 1947; Mantilla 1986, Mantilla 1995, Mantilla 2000a, Mantilla 2000b; Cobo Fray et al. 2011). Es plausible y, como tal lo aceptamos, suponer que este padre franciscano quitense escribiera a mediados del siglo XVIII al menos dos de los manuscritos con diversos textos de carácter evangelizador para su difusión por el área ecuato-colombiana; el primero de ellos elaborado en Quito en el año 1751, hoy día depositado en los fondos de la Real Academia de la Historia (Madrid) (Ms-RAH), sirvió de modelo de otros manuscritos copiados en fechas ulteriores que hoy se encuentran en distintas bibliotecas parisinas (Landaburu 1996), y el segundo, escrito probablemente en la etapa del padre Larrea en Popayán se halló en el Colegio Propaganda Fide de esta ciudad, carece de fecha y figura en el Índice de lenguas indígenas de la Biblioteca Nacional de Colombia (Bogotá) como "Raro Manuscrito 122" (Ms-BNC). El análisis comparativo entre esos dos manuscritos permite ver una relación de dependencia entre ellos (Carrera de la Red y Zamora

Micaela Carrera de la Red, Universidad de Valladolid, micaela.carrera@uva.es ORCID: http://orcid.org/0000-0002-8876-8449

D Open Access. (c) 2021 Micaela Carrera de la Red, published by De Gruyter. (c) BY-NC-ND This work is licensed under the Creative Commons Attribution-NonCommercial-NoDerivatives 4.0 International License. https://doi.org/10.1515/9783110701364-012 
2014, Carrera de la Red 2015). Los dos manuscritos contienen prácticamente el mismo "Vocabulario" bilingüe, con un número de 1625 entradas de una lengua general construida sobre la lengua siona (o ceona), si bien en el manuscrito de Quito $(M s-R A H)$ se añadió un "Breve compendio gramatical” y en el de Popayán $(M s-B C N)$ el autor-misionero colocó una selección de verbos delante del "Vocabulario" y en las páginas finales escribió la "Doctrina cristiana” compuesta de un catecismo y la preparación para la confesión según los mandamientos, así como otro listado, inconcluso, de "Vocablos para hacer más comprensible la lengua de estas misiones”. Además de estos dos manuscritos, se ha editado recientemente otro manuscrito (Gómez y Torres 2011), copiado hacia 1788 (obra, pues, de otra mano), perteneciente hoy a la Biblioteca del Palacio Real (Madrid) (Klein y Klein 1978: 137-144; Moreno Gallego 2009: 105-140).

\section{La región amazónica, área de contacto lingüístico por excelencia}

El proceso de contacto lingüístico continuo - según Klein y Stark (1985: 17) conduce a dos resultados, bien hacia la muerte de una lengua dada bien hacia la expansión de la misma. Esto último ocurrió en el área del río Vaupés, en la Amazonía central, con una concepción etnográfica fundamentada en la exogamia, en la cual eran y aún son frecuentes las conversaciones en dos o más lenguas, incluida la lengua de la casa comunal (longhouse language). Esto condujo a la extensión del tucano hacia regiones con otras culturas y se convirtió en lengua vehicular de comunicación entre diferentes grupos étnicos (Sorensen 1972[1967]: 78-93; Jackson 1974: 50-64; 1983; 2001: 373-396). La realidad etnográfica conocida sobre el grupo tucano occidental y sobre la nación siona (o ceona), en particular, confirma ese mismo tipo de cultura exogámica (Marín Silva 1993: 80-104), hasta el punto de que la nación "siona" tiene su nombre prestado de otra familia de lenguas de la Amazonía occidental, la uitoto, con el significado de 'gente del perfume' (Ortega Ricaurte 1997: 1146).

La dificultad a la hora de fijar la naturaleza de la lengua de estos textos deriva de la compleja realidad etnolingüística del área amazónica ecuato-colombiana (Rochá 1905). En el siglo XVIII, el misionero jesuita Gilij (1780, cit. por Jiménez de la Espada 1898-1899: 200) afirmaba ya que la lengua descrita y escriturada en los textos del padre Larrea se correspondía con la familia maipure, vinculada con la familia arawak y conformada por tribus de regiones cercanas a las Reducciones jesuíticas del Casanare y Meta. Gilij (1780), según cita de González Mora (2004: 33), afirmaba que "[el maipure] lo entienden todos en el gran río y se podría hacer común 
si se quisiera [. . . ] por lo tanto, de persistir el obstáculo de tantas lenguas. . ésta [la lengua maipure] sería bastante a propósito para hacer de ella una lengua general". No obstante, en fecha bastante posterior, Elías Ortiz (1942: 138), editor del manuscrito $M s-B C N$, afirmaba que, si bien era una "lengua general”, esta coincidía con la lengua siona, perteneciente al grupo occidental de la familia tucana, idea mantenida por Tovar (1961: 212) y Tovar y Larrucea (1984: 230).

En el estudio del cambio lingüístico inducido por contacto en esta área lingüística multilingüe, además de las familias de lenguas indígenas tucanas occidentales, es necesario tomar en consideración históricamente y en la actualidad la familia lingüística aimara-quechua en la costa y la sierra del actual Ecuador (Toscano 1953; Haboud 1998; Haboud y de la Vega 2008: 161-187; Muysken 1999: 89-114), así como en la región surandina colombiana (Vásquez de Ruiz 2000: 217-219, Levinsohn y Tandioy Jansasoy 2000: 121-134).

No es de extrañar que los misioneros franciscanos quitenses y payaneses, además del conocimiento de la lengua indígena instrumento de su tarea evangelizadora, ellos mismos pudieran ser hablantes bilingües o conocedores de alguna de esas lenguas. En el caso del padre Larrea se puede pensar en la posibilidad de que, al ser natural de Quito y desarrollar toda su actividad misionera en áreas con fuerte presencia de la familia lingüística quechua, fuera conocedor de la variedad ecuatoriana de esa lengua e incluso que fuera hablante bilingüe quechua-español, así como que tuviera conocimiento de lenguas tucanas (siona, koreguaje y sekoya), que perviven hasta la actualidad en el noreste del actual Ecuador junto con otras lenguas tucanas, mai huna, yagua y ticuna (Santos y Barclay 2005[1994]). Esto avalaría la conciencia adquirida de la necesidad de la construcción de una lengua general para comunicarse con los indígenas de toda aquella región. Para poder confirmar la hipótesis, se hace preciso analizar en los textos no solo de la parte de lengua indígena amazónica con el fin de ver el dominio por parte del misionero de la estructura de esas lenguas, sino también de la variedad de español utilizado en esos testimonios escritos, con el fin de observar si se trata de una variedad receptora de rasgos provocados o potenciados por contacto con alguna de las familias de lenguas indígenas de la zona.

\section{Mecanismos de contacto en el léxico de la lengua general}

Los lexemas del Vocabulario que recogió el misionero quitense muestran diferentes mecanismos relacionados con los cambios inducidos por contacto lingüístico, la mayoría de ellos propios de lenguas estrechamente relacionadas entre 
sí. La dinámica del contacto lingüístico conduce al autor-misionero a servirse de diferentes estrategias frente a una segunda lengua que está recogiendo y escriturando. La base del "Vocabulario" es la lengua siona, pero las lenguas amazónicas se configuran mediante la llamada "rutina del préstamo" con adaptaciones de los rasgos fonológicos de vocablos que comparte con otras lenguas de contacto (koreguaje, sekoya, uitoto, muinane-bora, piaparaná, etc.) (Dixon y Aikhenvald 1999; Petersen de Piñeros y Patiño Roselli 2000: 219-238; Escobar Pinzón 2000: 243-252). En el muestreo parcial que se recoge en (1), en la comparación uno a uno del léxico básico de Swadesh (1955: 121-137), seguido por etnógrafos y estudiosos de las lenguas indígenas (Landaburu 2000: 25-50), con los vocablos del "Vocabulario" y los resultados actuales en alguna de las lenguas amazónicas se observa una rutina de préstamos persistente:

(1)

\begin{tabular}{|c|c|c|}
\hline \multirow{2}{*}{\multicolumn{3}{|c|}{$\begin{array}{l}\text { Vocabulario } \\
\text { PIRAPARANÁ }\end{array}$}} \\
\hline & & \\
\hline “todos” siaye (todo, ó entero) & / si’’ajĕ//si’’ajĕ// & /sia’čé/ \\
\hline “malo" quámacá(cosa mala) & [k?u’?ahì & /kùámù/ \\
\hline "corteza" kaneo & [k?a?’ňiiwi] & [khàniru] \\
\hline "grande" jay (grande en cuerpo) & /'hai/ & /aiịue/hái \\
\hline “sangre” cié (la sangre) & /'zie/ & /jjél \\
\hline
\end{tabular}

Un paso más en la aplicación del mecanismo de "negociación" en la construcción del "Vocabulario" de la lengua general por parte del autor-misionero es la incorporación como léxico de esa lengua tucana general de préstamos de distinta procedencia. Por ejemplo, la entrada léxica Huacara - Una ave conocida por Guacharaca, es una adaptación a la grafofonología siona de un nombre de ave procedente de la familia caribe-arawak (Guacharaca) utilizado en Colombia y Venezuela hasta la actualidad. 0 también otras dos entradas más tomadas en préstamo de la familia aimara-quechua: Peri - Embuelto de mais, ó plátanos y Pirisonzo - Unos páxaros comedores de mais, ya que en el aimara actual de Bolivia existe piri como voz popular que significa 'alimento de consistencia pastosa, elaborado con harina, generalmente de maíz tostado, manteca, agua, sal y azúcar' (RAE-ASALE, DA 2010, s.v. piri). El segundo de los préstamos se construyó mediante un cruce derivativo con un predicado siona Sanzú - Mamar o chupar cañas, que se encuentra en el "Vocabulario", con lo que literalmente sería 'Maíz-chupar cañas'.

La definición de Guacha = En vano, ó momo (como) decimos yanga llanga ó illanga, en qquechua, en la que el autor-misionero se incluye a sí mismo a través de la forma verbal de primera persona de plural "decimos", nos permite pensar que el autor-misionero fuera bilingüe de español y quechua, o bien del kichwa 
de Quito, su ciudad de origen. La siguiente entrada es Guachahuaque = Hombre apacible y bonazo. La clave para abarcar los diferentes significados de la palabra Guacha ('en vano, momo, apacible, buenazo') está en la palabra quechua yanga (yanca), de la que se encuentran hasta tres entradas en el diccionario de González Holguín (2007[1608]: s.v. yanca): Yanca. Cosa baladí, ruin, desechada, sin valor ni precio, cosa sin provecho./Yanca yanca. Cosa de burla, o de poco más, o menos./ Yanca. Acaso no de propósito, ni de pensado ni con malicia, no con mal intento. El autor-misionero utiliza de nuevo el término yanga como préstamo plenamente incorporado al español, con el significado 'sin malicia', como se ve en (2).

(2) Tincoareca çizi yojoyenayeni yeo cani sique aquero? acajeca mueni painpacoa jucha canixenaeo inasique aquero?

Habéis aconsejado llevado o traído recaudo para que pequen? assí tambien, viendo que tus parientes andan en culpas, los has visto yanga?

Mención especial merecen otros préstamos del quechua en uso hasta el momento actual: Joyahiye = Uba camairona, con un sintagma nominal del término patrimonial más la especificación adjetival tomada del aimara-quechua. Es notable el hecho de que el misionero emplee la variante camairona, nombre común de esa uva silvestre, en lugar de la forma caimarona. Quere aro?= Y el locro?, en cuya equivalencia española se hace referencia al locro (quechua ruqru o luqru), un vocablo de la lengua popular con el que se nombra una suerte de guiso típico de varios pueblos andinos (Argentina, Bolivia, Perú o Ecuador). Túhikan - Vestuario de mujer, ó anaco, vocablo este último definido como rural en Perú y Ecuador (RAE-ASALE, DA, s.v. anaco).

Por último, es destacable el cruce entre español y siona: Aguardiente ructa sotoro = el alambique, que significa exactamente 'Aguardiente - sacar - olla de barro'.

Si se presta atención al equivalente léxico-semántico en español para los vocablos de la lengua tucana, el "Vocabulario" está lleno de estas imprecisiones, tal como se advierte en el dominio semántico de 'fruta', cuyas equivalencias son del tipo "fruta", "fruta como quiera", "una fruta" o "fruta de este árbol”. En otras ocasiones, la equivalencia se resuelve con vocablos de distintas lenguas indígenas generales totalmente integrados ya en español: del caribe-arawak, Joyapenne = guabas bejucas, fruta/Sisipenne = guabas de mono, fruta/Súipenne = guabas de apuji, fruta; caribe-arawak y nahuatl unidos: Eneyaji = Batata ó camote; nahuatl y quechua juntos: Ocotin = Totumo, ó mate regular; del nahuatl: Gueague = Masorca de maís, ó la tusa, Pia = El ají, ó pimienta. 


\section{Cruce de español en la lengua tucana de la "Doctrina"}

En los textos doctrinales se mantiene el contenido tradicional de este tipo discursivo desde los inicios de la evangelización en el siglo xvI, así como la estructura pregunta respuesta (Carrera de la Red 2004: 327-340). Además, a la hora de trasladar aquellos referentes conceptuales de la doctrina del cristianismo a la lengua indígena, el misionero se sirve de los vocablos españoles, según una tradición muy fuerte entre los padres franciscanos que llega hasta el siglo XIX (Zwartjes 2016: 43-76; Van de Kerke 1999: 115-149).

\section{Doctrina Christiana}

P.- Quegame zjincoa Dios pay quero?

Decidme, hijos, si hay Dios?

R.- Dios paymue Padre

Sí, Padre, Dios hay

P.- Kesamo Dios pay quero?

Cuántos Dioses hay?

R.- Teheque Dios amue

Uno solo, no más

P.- Jij Dios caro-na pay quero?

Dónde está este Dios?

R.- Ocomue-na Yao yeja-ro, siarogue-te pay-mue

En el cielo, en la tierra, y en toda parte y lugar

P.- Nebi Dios a-yero?

Quien es Dios?

R.- La Sanctissima Trinidad.

P.- Nebi Santissima Trinidad aquero?

Quien es la Santíssima Trinidad?

R.- Dios Jaque, Dios Zijn, Dios Espíritu Santo, samuyuteyque persona, teseca Dios amue

Dios Padre, Dios hijo, Dios espíritu Santo que son tres personas distintas y no mas que un solo Dios 
P.- Jaque Dios aquero?

El Padre es Dios?

R.- Acame Padre

Sí, Padre.

P.- Samuyuteique Dios paî quero?

Ay tres Dioses?

R.- Pañe Padre tehaseca Dios amue

No Padre, es un solo Dios no más

P.- Caro-na pain-que ruins-i-que a-quero?

Donde se hizo hombre?

R.- Mayl Jaco Maria Santisima ketaro-na painque, ruin-si-que amue

En el vientre de Ma. SSma. Nra Sra se hizo hombre

P.- Keanca, painque, ruinsique aquero?

Como se hizo hombre?

R.- Espiritu Santo nehe-sique amue, pain que ne maisique amue El espíritu Sto. Lo hizo, mas no como los hombres.

P.- Jihi Dios Zijn painque ruinsique, in quimamiquequero?

Este Dios hijo despues de hecho hombre como se llamo?

R.- Jesuchristo mami amue.

Se llamo Jesuchristo.

P.- Nebi Jesu Christo ayero?

Quien es Jesuchristo?

R.- Dios reba painque reba ame

Es Dios y hombre verdadero

P.- Jihi Jesuchristo mayni oique, en quere neherero?

Este Jesucristo, que hizo por nuestro amor?

R.- Cruz tupuena Juisique amue, mayre Jucha teasaniye

Murio en la + por librarnos de nuestros pecados

P.- Juisiete yoje sehe guajesique aquero?

Y despues de muerto, boluio a vivir?

R.- Acame Padre

Sí, Padre

P.- Guajenica carona Satero?

Despues de viuo donde esta? 
R.- Ocomuena muhisique amue.

Subio a los Cielos.

P.- Muhisiete yoje sehe raisaque nequero?

Y despues de aver subido ha de bolver?

R.- Acame Padre.

Sí, Padre.

P.- Enque rempi raysaque neye?

En qué tiempo ha de venir?

R.- Juicio vmuguze raysaque neye

El dia del Juiçio ha de venir

P.- Enque nehe-saniye?

A que ha de [venir]?

R.- Siacoareca, guajicoareca Juicio?

[...]

R.- Keanca guajirero, seen saniyenayeni, raysaque nenê

Ha de venir a preguntar a todos los vivos y a los muertos como han vivido?

P.- Deoye guajesicoareca enquere insijaque aquero?

A los que han vivido bien, que les ha de dar?

R.- Ocomuena insisaque ney[ $\left.{ }^{\star \star}\right]$ inque Yeo regua $\left.{ }^{[\star \star}\right]$ sicoareca

Les dara el çielo a los que guardaron su palabra o mandamientos.

P.- Quaye guajesi-coa-reca, enque-re, insijaque a quero? +

A los que han vivido mal, que les ha de dar?

R.- Jai-toa-re, insisaqueneye, inque Yeo, re guamaysicareca.

Les dara un gran fuego, por no aver guardado su palabra o mandamientos.

P.- Mosacoa rocta toja-ro enque-re jai-toca?

Que pensáis vosotros, que es esse gran fuego?

R.- Jaarogueca, Yaoyeja sanaunte, Jaohuaticoa; payro gueca, hacoa mamipeocoare, christiano-coa taxi, deoye, guajimaysi-coa-reca, vye paisaque neye Kerenjeca. Allá dentro de la tierra donde están los demonios han de tener a los gentiles; y a los malos christianos, quemándolos para siempre

P.- Deoye guajesicoareca, enquere ocomuena insijaquero?

A los que vivieron bien, que les dara en el cielo?

R.- Inque yeo reguasicoa, insisaque neye, soeguajeyete, Kerenjeca may pojoye, pay jaroguete enquegue auncicayeca enque que rabuejeca peo mue A los que guardaron Su Santos mandamientos Les dara vna vida alegre y larga para siempre, donde no habrá ninguna neçessidad, ni menos enfermedad. 
P- Mosa-coa ['?] octa paitoca senseguay xemaca juitoaro, keanca Dios harogueca deorogue, insisaquenenê?

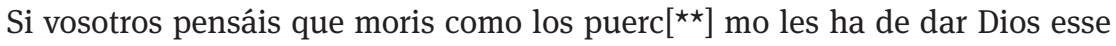
lugar?

R.- Maireca, Zenseguay Xentaca may alma ectaquena canibue juisie se he juicio vmuguzepi may canibue guajisa quenene;[ocotroro ${ }^{\star \star}$ ] aitica deoye guajesicoareca alma canibuena quajoni ocomuena saisaquenene. Quaye guajesicoareca alma canibuena quajoni vye sayjaquenemue kerenjeca

\section{Acto de contrición}

+ Nosotros no morimos como los puercos, saliendo el alma que vivieron mal iran en cuerpo muere el Cuerpo; pero el dia del Juicio ha de volver a vivir Juntandose con el alma. Y entonces los que vivieron bien guardando la ley de Dios iran en cuerpo y en alma a la gloria; y los que vivieron mal, iran en cuerpo y en alma a quemarse en el infierno para siempre.

P.- Confesai ega quero?

Quieres confesarte?

R.- Ega-ye, Pañe

quiero $=$ no quiero

P.- Kesamo erem conffesa-mai-sique aquero?

Quanto tiempo ha que no te conffiesas?

[...]

Junto a Dios, la Santísima Trinidad, Dios, Espíritu Santo, María Santísima, Jesu Christo, Cruz, o vocablos abstractos o genéricos como alma y persona, el español y la lengua siona se mezclan en expresiones lexemáticas como Dios Jaque ('Dios Padre'), frente al uso del vocablo Padre con el significado de 'sacerdote', y frente al vocablo siona que recoge en el "Vocabulario": Jaque - padre, en proto-tucano pak-i (masc.) (Welch y West 2000: 427), Dios Zijn ('Dios hijo'), o Juicio vmuguze ('Juicio día' = 'día del juicio'). Se forma el plural de vocablos españoles con el derivado sufijal siona: cristianocoa 'cristianos', o se conjuga el predicado con la raíz hispánica y el sufijo de voz media siona -i (Wheeler 2000: 189): confesai 'confesarte', o a la misma raíz se incorpora la marca de negación y la desinencia de segunda persona: conffesa-mai-sique 'no te confiesas'. Las referencias al 'infierno' $\mathrm{y}$ al 'demonio' se expresan totalmente en siona: Jaarogueca, Yaoyeja sanaunte, Jaohuaticoa 'Allá dentro de la tierra donde están los demonios'. 
(4) P.- Mosacoa jaitoa?

rocta toja-ro enque-re

Vosotros PRON-2PERS-PL pensar INTERROG que-INTERROG - COMPLESPEC grande en cuerpo -fuego'

Que pensáis vosotros, que es esse gran fuego?

\section{Conocimiento e interpretación de la gramática de las lenguas tucanas}

El padre Larrea era un buen conocedor de la tradición gramatical latina, pero también poseía un buen conocimiento de la estructura interna de las lenguas amerindias. De nuevo muestra un alto nivel de cruce entre distintas lenguas del grupo tucano, un rasgo que es constante en la morfosintaxis nominal (Carrera de la Red 2016). En su "Breve gramática” afirma que "Todos los nombres son declinables, y se declinan sin diferencia con una misma declinación” (Ms-RAH); en esta lengua indígena los "casos” son las marcas relacionales que actúan entre los nombres y los otros constituyentes de los enunciados y que aparecen sufijados a los núcleos nominales (Dupont 1989: 37). Como modelo de declinación sitúa el nombre no contable e inanimado Ocó = el agua ([ro'ko]), una raíz simple que equivale al nominativo; la marca derivativa -quéhe (Ocoquéhe) se usa de forma obligatoria en construcciones posesivas, por lo que se equipara al genitivo; -náyeni (Oconáyeni) se señala como marca de caso dativo porque contiene -ni marcador de caso de complemento indirecto, a la vez que puede señalar énfasis; la marca -ná (Oconá), identificada como acusativo, es una marca multifunción que señala también 'destino'. En cambio, el caso que señala como ablativo tiene una marca sufijal -nacohoni (Oconacohoni), cuya variante -nacooni (sin marca gráfica de glotalización) aparece incorporada al pronombre personal de primera persona singular Yé, en función de 'compañía’: Yénacooni - Conmigo (Yé-nacooni).

La macroestructura del "Vocabulario" se organiza en torno a la categoría gramatical de género, un marcador derivativo muy consistente en los nombres animados con cualidades en femenino señalado con la marca - $c o$, que es común a las lengua siona y koreguaje (Zijnsico = Mujer preñada), mientras que los nombres no femeninos (o masculinos) se marcan con la forma de la lengua siona -que: Toiaque = el que escribe o pinta, gramaticalización sobre el predicado Toia = pintar, escribir o bordar.

El marcador de número -coa coincide con la marca de plural [- $\left.\mathrm{k}^{\mathrm{w}} \mathrm{a}\right]$ de la lengua siona actual: el plural de Ocó 'agua' es Ocócoa = Las aguas. Este nombre, en concreto, pertenece a realidades naturales que se presentan como magnitudes no ligadas o entes masivos: aire, agua, lluvia, nieve, barro, hierba, con referentes 
no contables. Por el contrario, otro grupo de nombres relacionado con el cuerpo humano o animal se construye con la forma afijal - $a$, perteneciente a la lengua koreguaje: Zitaméa $=$ Las venas, Ketamea $=$ Las tripas, Ráná = Cabellos, pelo, ó bello. Se encuentra también el sustantivo animado colectivo plural Ayrue $=$ Los antipasados ó mayores (Ms-RAH) Ayhue = los antepasados, ó mayores (Ms-BNC), próxima al uitoto, tal como se recoge en un diccionario de esta lengua amazónica, en el que aparecen diversas entradas similares: Eiroma 'hombre viejo', Eirue Jito 'a nuestros antepasados, a los primogénitos (lit. a las gentes que fueron creadas primero) (Wise 1983: 75-76).

Sobre la base léxica guai/guay 'carne' se forma uno de los clasificadores o morfemas de sufijación más productivo del "Vocabulario": -guay/-cuay, que hace referencia a 'especie genérica, animado, animal'. Es común al siona, al tucano y al pisamira. Durante el siglo XVIII, Gilij (1780: libro V, p. 276) recoge tenbiguài como nombre de un tipo de insecto, en español "el mosquito bobo o de la miel", en lenguas de las tribus del Orinoco, en concreto de las familias lingüísticas tamanaco y maipure.

En la cita de la "Breve gramática” se señala también el carácter sufijal que posee el "clasificador” relacional para la negación -mai.

(5) El término Mai, cuando se pronuncia solo, significa Nosotros, y equivale á Yequina; pero si se pone después de verbo, significa negación; v.gr.: Bica = Hablar. $=$ Bicamay $=$ No hablar. $=$ Rai $=$ Venir. $=$ Raimai $=$ No venir. Y así en todos los verbos (Ms-RAH).

Además de la posición sintáctica enclítica al predicado del morfema de negación, la diferencia entre ambos términos estriba en la naturaleza diversa de la pronunciación: nasalización y pronunciación diptongada en la forma mai 'nosotros' (/mai/['mãĩ]) y glotalización y separación silábica en la forma -mai como afijo de negación ([-ma’ri]) (Wheeler 2000: 183-192).

\section{Rasgos de una variedad popular en el español ecuatoriano}

La variedad de español del padre Larrea presenta ciertos rasgos del español coloquial del área andina ecuatoriana. Así, en el léxico aparece Kétacóje = El estantino, un vocablo español equivalente con una etimología popular que se usa actualmente en lugar de "intestino" en la costa de Ecuador, según recoge Toscano Mateus (1953: 135). 
En morfosintaxis aparecen ciertas locuciones adverbiales: Tehéyóje $=$ En una vez, Séhéyóje = En otra vez, esta segunda documentada históricamente de forma principal en Ecuador; Yuctareba = Poco há, ó aora poco; de la segunda definición solo hemos encontrado un ejemplo literario citado por Toscano Mateus (1953: 158): "no teníamos noticia hasta ahora [ha] poco tiempo (J.L. Mera, Ojeada, p.175)”. Deoquena = Diz que está bueno, Deomayquena = Diz que no está bueno son dos entradas en siona formadas por una verbalización del adjetivo masculino (Deoque) mediante un afijo modal -na, que en siona indica cambio de sujeto; este afijo le sugiere al autor una construcción del español hablado popular ecuato-colombiano con la forma dizque disque, un medio para cambiar de emisor y expresar duda ante lo que sigue.

\section{Rasgos atribuibles al contacto español - quechua}

En el español del autor-misionero se percibe el influjo de las estructuras de la gramática de las lenguas indígenas con las que estaba en contacto no solo por la tarea de descriptor y compositor de una lengua tucana general, sino también porque él mismo fuera conocedor y hablante de una de esas lenguas, en concreto de la variedad quitense o ecuatoriana de la lengua quechua.

Palacios (2006: 46) cifra la influencia de la lengua quechua en el español ecuatoriano, entre otros, en los siguientes rasgos caracterizadores de esta variedad de español andino, compartidos en gran medida - según esta autora - por otras variedades andinas del español (colombiana, argentina, boliviana o peruana): "la reestructuración del sistema pronominal, las construcciones de gerundio, las formas de atenuación de órdenes, ruegos, la reestructuración de los tiempos verbales de pasado hacia valores modalizadores o evidenciales, el uso de diminutivos, las discordancias de género y número o las alteraciones en el orden de constituyentes”. Un buen número de esos rasgos de cambios inducidos por contacto puede rastrearse, en mayor o menor medida consolidados ya, en el español del misionero quitense.

\subsection{Tratamientos con predicado de modalidad yusiva}

En (6) se recogen los abundantes predicados en imperativo con el morfema sufijal -me del siona (Wheeler 2000: 191). En las equivalencias del español, es visible la oposición de los tratamientos en la modalidad yusiva entre las formas 
del tú y las del vos, en este último caso con formas verbales no diptongadas. Un tercer grupo con formas verbales admiten la doble posibilidad de tratamiento tú/vos, ya que, al carecer de los diacríticos, las formas verbales admiten una doble posibilidad en la pronunciación: llana (forma de tuteo) o aguda (forma de voseo): Cacame = entra (tú)/entrá (vos). El "Vocabulario" recoge para la misma forma del pronombre de segunda persona, Mué - Tú, o vos, la función doble que

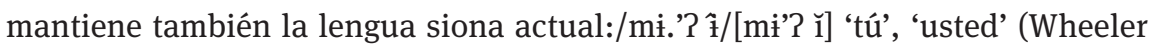
2000: 183). El plural del imperativo (coincidente en la lengua siona al singular) se hace equivaler en español con la forma vosotros. En los ejemplos recogidos bajo (6) mantenemos la ausencia de acentuación por no predeterminar el tratamiento que encierra cada una de ellas; tan solo nos centramos en la forma del predicado.

(6) Singular:

(a) Tú: Queresayme = apartate un poco, da lugar, Quereraime $=$ Ven un poco para acá, Huejame $=$ Casate, Apume $=$ Labate, Kanjaome $=$ arropate, Guame $=$ Baçia, Yuire huesseme $=$ has ovillo $\mathrm{u}$ ovilla

(b) Vos: Tereme = cerra, o cerca, Paynehe hueseme = haze dulce, Chafame $=$ rega, Jongome $=$ frega, Pecteme $=$ Segui, Jocame $=$ dexa, Neheme $=$ haze, Uhame $=$ pone, Ectame $=$ Sali, Guese-na ectame $=$ Sali afuera, Cuarume $=$ herbe, Toame $=$ Mole, Suhume $=$ Cerni, Seome $=$ encende, Sapime $=$ espremi, Jectome $=$ de, Ensenaquename $=$ seca 0 calenta al sol, Tebame $=$ pone al través, Keome $=$ Calenta, Oyame $=$ Torçe, Yeeme $=$ ole, Ynõme $=$ mostra o señala, Jancome $=$ abri, Yime $=$ deçi, Guaguame = quebra, Sectame : desperta, Ujeme = sembra, Raamaxaque Yihime $=$ deçi que no traiga

(c) Tú/Vos: Picegame $=$ sentate, Cacame $=$ entra, Zunãme $=$ Mete, Toctame $=$ golpea o magulla, Cueme $=$ busca, Soame $=$ Laba, Cuacome $=$ cosina, Cuename $=$ seca, Xejeme $=$ embarra, Yohame $=$ barre, Teonme $=$ espessa, Sahame $=$ lleba, Sahome $=$ embia, Tincoamiroime $:$ achaca a otros, Saniteame $=$ anda quita, Mename $=$ acaricia, Kereme $=$ aguza, Cajeme $=$ baxa, Choime = llama, Pejeme = trabaja, Quajome = acompaña, Yename $=$ enbetuna, Ketome $=$ afita, Yeiome : enseña, Yehuame $=$ nada, Yohome $=$ enlasa, Yojuame $=$ Palanquea, Yigtime $=$ rasga, Gueame $=$ alza, Gueeme $=$ Carga, Guegueme $=$ corre, Jnsime $=$ da, Ruame $=$ afirma, Cuayuiume $=$ sala, Tenome $=$ ensarta, Suijaime $=$ brinca, Quereraome $=$ embiame o trae un poco, Guay Guay Jaime = anda, mata carne 
Plural:

(d) Vosotros: Coime $=$ volveos, Ejame $=$ quedaos, Ejome $=$ esperaos, Paiquepay : quedaos o estaos

(e) Vosotros con negación: Sahomayme $=$ no embieis, Sahamayme $=$ no llevéis

Sobre el contexto de uso de una $u$ otra forma de tratamiento, pese a ser ambas construcciones de tipo yusivo e imperativo, las frases bajo (2.a) denotan cierto grado de proximidad y cercanía entre el emisor y el destinatario, mientras que las formas bajo (2.b) denotan una cierta distancia, si bien resulta difícil medir con certeza el grado de respeto que encierra el tratamiento con vos frente al tú, una situación que en la actualidad se resuelve con un tercer pronombre de tratamiento, usted (Haboud y De la Vega 2008: 173).

\subsection{Construcciones con gerundio}

En la "Breve gramática”, las diferentes formas de gerundio del verbo Bica = hablar que detalla el misionero se sitúan bajo el rótulo "Infinitivo". Allí se ve la diferencia claramente establecida por el autor-misionero entre tres formas de gerundio en la lengua tucana y su correlato bien marcado en español: un gerundio simple $($ Bicani $=$ Hablando), un gerundio preposicional (Bicatoca $=$ En hablando) y un gerundio compuesto (Bicaquena =Haviendo hablado), lo que implica valores de uso claramente diferenciados entre las tres.

(7) Bicani $=$ Hablando

Bicatoca $=$ En hablando

Bicaquena $=$ Haviendo hablado

Bicaienayeni $=$ Para hablar ó por hablar

Bicaséroye $=$ Por lo hablado

Bicaseé = Cosa hablada, ó lo hablado

Los sufijos -ni, -to en siona sirven para expresar el primero 'acción definida' y el segundo ‘acción indefinida' en la condición, con el sufijo -ca se añade además 'condición de otro suceso', y expresan también la concesión (Wheeler 2000: 192).

La entrada Anaacachani = Oyendo esto, con el sufijo -ni literalmente es Anaacachá-ni 'esto-oir-acción definida'. La forma de gerundio del español, sin contexto enunciativo más explícito, resulta un tanto difícil de analizar en su función más allá de que es gerundio simple, quizás con valor de construcción absoluta, equivalente a la 'acción definida' del sufijo tucano y al valor "perfectivo” del gerundio 
del español ecuatoriano (Haboud 1998: 204-208), que podría adquirir valor condicional siempre que el predicado principal fuera referido al futuro.

Las entradas Ahyntoca $=$ En comiendo, Egatoca $=$ En queriendo, Egamaytoca $=$ En no queriendo, con los dos sufijos -to-ca indicarían 'acción indefinida con la condición de otro suceso' y su equivalente con gerundio preposicional, una forma no muy frecuente en el español estándar actual, pero que, cuando aparece, porta la función de "anterioridad inmediata" a la acción del predicado principal (RAEASALE, NGLE 2010: 518). Las construcciones equivalentes en español tanto en gerundio simple como en gerundio preposicional a la construcción del siona con subordinada condicional, se ve de forma clara, en su función condicional, en las entradas en las que hay una oración principal en imperativo: Raatoca quegame = trayendo avisame, Raamaytoca, quegame = en no trayendo avisame, Ciaya reosilla paitoca saymayme = estando el rio cresido no vayas, Nehetoca rahame = en haziendo trae. En medio de todos estos ejemplos, aparece una oración condicional que equivale en español a la construcción de acción indefinida con la condición de otro suceso del siona.

(8) Muepi Yeni Ynsimaytoca ye jeca insimaixaque $=$ si vos no me dais, yo tanbien no te daré.

Vosotros-a mí-dar-NEG-COND yo-ninguna cosa-dar-NEG-FUT

Aparecen formas de gerundio no preposicional con verbo finito de movimiento: Neheni texini, rayme = acabando de hazer veni, Hinirayme = traiendo veni, Cajeni hijayme = Bajando anda trae, Saiquepai = anda caminando, Ciaya gueaquena saime = en baxando el rio anda. Estos ejemplos están muy próximos a los usos como “deíctico de acercamiento" o de modalidad continuativa que se registran en la actualidad entre bilingües de kichwa y castellano así como entre monolingües hispanohablantes de la Sierra ecuatoriana (Haboud 2005: 9-38). El gerundio con verbos de movimiento en contexto oracional de imperativo, contribuyen a atenuar el mandato.

En la preparación para la confesión de la "Doctrina cristiana", una de las preguntas contiene un uso del gerundio no sabiendo como equivalente al vocablo siona Guacha, entre cuyos significados estaba 'en vano', 'no a propósito', al que ya se hecho referencia en la Sección 6 de este trabajo a propósito del quechua yanga yanca:

(9) Guacha mansi mayto bicasee cuina [**] circo ana cohoni acamayxi Yihimaysique aquero?

Lo que hablaste no sabiendo, con aquellos mismos que hablasteis, no les dixisteis que no era assi? 
De acuerdo con la literalidad de la expresión siona Acaquena = Siendo así, formada con un adverbio de certeza y dos sufijos: 'hã?'ka-que-na 'así-Acción pasada anterior-Cambio de sujeto', el gerundio se utiliza para expresar el significado de certeza completa hacia el pasado.

\subsection{Objeto directo nulo}

En diferentes ejemplos de construcciones con gerundio de anterioridad, su estructura se acompaña de otro rasgo característico del español quiteño: el grado cero en el objeto directo pronominal átono de tercera persona, fenómeno potenciado por el contacto con el quichua, lengua que carece de este rasgo gramatical (Palacios 2006: 197-230; Palacios 2015: 104-130). En estos ejemplos, el clítico iría pospuesto: Nehetoca rahame = en haziendo Ø trae $\emptyset$, Hinirayme = traiendo $\emptyset$ veni, Cajeni hijayme = Bajando and a traeØ, Tehecanco huatixe paix ihijayme = a un lado esta el maçhete, traeØ.

\subsection{La expresión de certeza completa en pasado}

En siona la marca sufijal verbal -xi aparece vinculada a la expresión de la certeza completa: Emuebi payxi = arriba está, Yeja payxi = abajo está, Deoxi = bueno está, Serejayxi = está frio o esta dulce, Hueocaixi = esta con sueño, Azinehexi = esta lastimado, Puinxi = esta brabo, Guaysenxi = esta sabroso, Tunexi = esta redondo, Yraxi = esta viejo, Guimayxi = no esta lleno. Otra posibilidad de expresión de la acción completada en siona es el uso del sufijo clasificador -pi: Longuepi = esta tuerto, Huepi = esta atajado (Wheeler 2000: 190). La perífrasis aspectual de alto grado de certeza: Deoyepai dasquenexi = ha de estar bueno.

Ahora bien, en las lenguas siona y koreguaje actuales la expresión de la acción completa o terminada se sirve de una forma sufijal -si (-xi) incorporada a verbos en presente pero, sobre todo, en pasado inmediato (Wheeler 1970: 65, 2000: 190; Rodríguez González 2000: 206). Se trata de un tipo de evidencialidad indirecta o "reportativa", que poseen lenguas como el siona ecuatoriano actual o el quechua del Cuzco (Bruil 2014: 249-263). El significado que expresa es el de que el hablante puede no haber presenciado la acción, sino que tiene conocimiento indirecto del hecho. Así, por ejemplo, del verbo Cai $=$ Resbalar, Caixi $=$ ha resbalado, o resbaló, del verbo $A z i=$ doler alguna parte del cuerpo, $A z i n e e x i=S e$ lastimó, Tunexi = ha rodado, Yejabitoinxi = ha caido abajo. 


\section{Observaciones finales}

El análisis de estos textos muestra lo difícil que resulta especificar a qué lengua pertenece cada uno de los rasgos lingüísticos que se analizan en una situación de contacto lingüístico (Thomason 2005[2001]: 85; Chacon 2012, Chacon 2014: 177). El Padre Fray Jesús María Larrea nos dejó uno de los escasos y más valiosos testimonios que se conservan referidos a esa compleja realidad etnolingüística de la región amazónica ecuato-colombiana en el siglo XVIII. Sus textos misioneros ofrecen una muestra de los intensos cruces existentes en la distribución de los fenómenos lingüísticos de las lenguas amazónicas entre sí y con el español, que se ve impregnado, en el léxico y en la estructura gramatical, de la dinámica del contacto en las fechas de la composición de estos textos, mediados del siglo xviii.

El padre franciscano, en consonancia con el entorno de lenguas amazónicas en el que se desenvolvía su acción evangelizadora, manejó con soltura el contacto de lenguas en su acción misionera con la ventaja más que probable, según queda constatado a través de estas páginas, de ser él mismo hablante de otra lengua indígena, el quichua de Quito, ciudad en la que nació y que se traduce en una variedad del castellano que recoge un buen número de rasgos surgidos del contacto. Merecen ser citados los ejemplos con objeto directo nulo, rasgo de un castellano en contacto con el quichua quitense, o aquellos enunciados en los que se recoge la expresión de la certeza completa en el pasado propia de la lengua siona. No obstante, el rasgo más destacado de una variedad de castellano del padre Larrea con cambio lingüístico potenciado por el contacto es la presencia de numerosos ejemplos de las formas de gerundio, portadores de una gran riqueza de matices sintáctico-semánticos que, en gran medida, pueden atribuirse al contacto con las lenguas originarias del área ecuato-colombiana de la Amazonía occidental.

\section{Referencias bibliográficas}

Barnes, Janet, Alva Wheeler y Margaret Wheeler. 1992. Estudios comparativos: Proto tucano. Bogotá: Editorial Alberto Lleras Camargo.

Bruil, Martine. 2014[1982]. Clause-typing and evidentiality in Ecuadorian Siona. Utrecht: LOT/Netherlands Graduate School of Linguistic. URL: http://hdl.handle.net/1887/23938.

Carrera de la Red, Micaela, 2004. El "catecismo" y la "cartilla” de Fray Dionisio Sanctis en el marco de la lingüística misionera colombiana. En Cristóbal Corrales Zumbado, Josefa Dorta, Dolores Corbella Díaz, Antonia Nelsi Torres González, Francisca del Mar Plaza Picón, Laura Izquierdo Guzmán, Mํㅡㄹ Auxiliadora Martín Díaz, Javier Medina López, Beatriz Hernández Díaz (eds.), Nuevas aportaciones a la historiografía lingüística, 327-340. Madrid: ArcoLibros. 
Carrera de la Red, Micaela. 2015. Variantes grafémicas y correlatos fonológicos en la lengua tucana de un Vocabulario de la Amazonía ecuato-colombiana (siglo xviii). Comunicación oral en el XLIV Simposio de la Sociedad Española de Lingüística. Sección “Lenguas Indígenas". CCHS-CSIC, Madrid, 27-30 de enero de 2015.

Carrera de la Red, Micaela. 2016. Mecanismos clasificadores en el tucano accidental del Vocabulario de la lengua general de los indios del Putumayo y Caquetá (siglos xviii y xix). Comunicación oral en el Congreso Internacional de Español de América: Historia y Contactos. Pisac, Cuzco, 12-15 de julio 2016.

Carrera de la Red, Micaela y Francisco José Zamora Salamanca. 2014. Un intento de configuración de lengua general en el sur de Colombia: el Vocabulario de la lengua general de los indios del Putumayo y Caquetá. Comunicación oral en el VIII Congreso Internacional de Lingüística Misionera. Lima, PUCP, 25 al 28 de marzo 2014.

Chacon, Thiago. 2012. The phonology and morphology of Kubeo: The documentation, theory and description of an Amazonian language. Hawai: Tesis doctoral de la University of Hawai.

Chacon, Thiago. 2014. A revised proposal of Proto-Tukanoan consonants and Tukanoan family classification. International Journal of American Linguistics 80(3). 275-322.

Cobo Fray, Constanza, Erick Figueroa Pereira, Isabel Urriago Avendaño y Juan Pablo Rada Quesada. 2011. Colegios de Misiones Franciscanos. Valoración histórica de los colegios de Nuestra Señora de las Gracias, en Popayán y de San Joaquín, en Cali. Cali: Universidad de San Buenaventura.

Dixon, Robert M. Ward y Alexandra Y. Aikhenvald (eds.). 1999. The Amazonian Languages. Cambridge: Cambridge University Press.

Dupont M., Carlos. 1989. Clasificación nominal en la lengua Koreguaje. Forma y Función 4. 35-46.

Elías Ortiz, Sergio. 1942. Bocabulario de la lengua que usan los indios de estas misiones. Ceona. Revista de Historia. Centro de Historia de Pasto 2. 137-199.

Escobar Pinzón, Rosa Alicia. 2000. Aproximación a la fonología del bora. En María Stella González de Pérez y María Luisa Rodríguez de Montes (eds.), Lenguas indígenas de Colombia: una visión perspectiva, 243-252. Bogotá: Instituto Caro y Cuervo.

Gilij, Filippo Salvadore. 1780. Saggio di Storia americana, o sia, Storia naturale, civile e sacra de regni e delle provincie Spagnuole di Terra-ferma nell'America meridionale. Roma: Vaticano nella Sapienza.

González de Pérez, María Stella y María Luisa Rodríguez de Montes (eds.). 2000. Lenguas indígenas de Colombia: una visión perspectiva. Bogotá: Instituto Caro y Cuervo.

González Holguin, Diego. 2007[1608]. Vocabulario de la Lengva General de todo el Perv llamada Lengva Qquichua o del Inca. Lima: Imprenta de Francisco del Canto (online grupo Runasimipi Qespisqa Software, URL: www.runasimipi.org).

González Mora, Felipe. 2004. Reducciones y haciendas jesuíticas en Casanare, Meta y Orinoco. S. XVII-XVIII. Arquitectura y urbanismo en la frontera oriental del Nuevo Reino de Granada. Bogotá: Editorial Pontificia Universidad Javeriana (Colección Biblioteca del Profesional).

Haboud, Marleen. 1998. Quichua y castellano en los Andes ecuatorianos: los efectos de un contacto prolongado. Quito: Ediciones Abya-Yaba.

Haboud, Marleen. 2005. El gerundio de anterioridad entre bilingües hispanohablantes de la Sierra ecuatoriana. Universos. Revista de Lenguas Indigenas y Universos Culturales 2. $9-38$. 
Haboud, Marleen y Esmeralda de la Vega. 2008. Ecuador. En Azucena Palacios (ed.), El español en América. Contactos lingüísticos en Hispanoamérica, 161-188. Barcelona: Ariel Letras.

Jackson, Jean. 1974[1983]. Language Identity of the Colombian Vaupés Indians. En Richard Bauman y Joel Sherzer (eds.). Explorations in the Ethnography of Speaking, 50-64. Nueva York: Cambridge University Press. (Traducción: Identidad lingüística de los indios colombianos del Vaupés. Lenguaje y sociedad, 379-398).

Jackson, Jean. 1983. The Fish People. Linguistic Exogamy and Tukanoan Identity in Northwest Amazon. Cambridge: Cambridge University Press.

Jackson, Jean. 2001. Treinta años estudiando el Vaupés: Lecciones y reflexiones. En Carlos G. Zárate y Carlos E. Franky (ed.), IMANI MUNDO: Estudios en la Amazonia colombiana, 11-51. Leticia: Universidad Nacional de Colombia/Instituto Amazónico de Investigaciones.

Jiménez de la Espada, Marcos. 1898-1989. Vocabulario de la lengua general de los indios del Putumayo y Caquetá. Revista de Archivos, Bibliotecas y Museos, 200-216, 258-263, 427-432, 527-529, 575-577; 187-191, 358-362, 518-520.

Jiménez de la Espada, Marcos. 1904. Vocabulario de la lengua general de los indios del Putumayo y Caquetá. Madrid: Rev. de Archivos, Bibliotecas y Museos.

Klein, Harriet E. M. y Herbert S. Klein. 1978. The 'Russian Collection' of Amerindian Languages in Spanish Archives. International Journal of American Linguistics 44(4). 137-144.

Landaburu, Jon (comp.). 1996. Documentos sobre lenguas aborígenes de Colombia del archivo de Paul Rivet. Vol. I: Lenguas de la Amazonia colombiana. Bogotá: Ediciones Uniandes/ Centro Colombiano de Estudios de Lenguas Aborígenes Colciencias.

Landaburu, Jon. 2000. Clasificación de las lenguas indígenas de Colombia. En María Stella González de Pérez y María Luisa Rodríguez de Montes (eds.), Lenguas indígenas de Colombia: una visión descriptiva, 25-50. Bogotá: Instituto Caro y Cuervo.

Larrucea de Tovar, Consuelo. 2012[1984]. José Celestino Mutis (1732-1808) and the report on american languages ordered by Charles III of Spain for Catherine the Great of Russia. En Antonio Quilis y Hans Josef Niederehe (eds.), The History of Linguistics in Spain, 213-231. Amsterdam: John Benjamins (Historiographia Linguistica XI).

Levinsohn, Stephen y Francisco Tandioy Jansasoy. 2000. Inga. En María Estella González Pérez y María Luisa Rodríguez de Montes (eds.), Lenguas indígenas de Colombia: Una visión descriptiva, 121-134. Bogotá: Instituto Caro y Cuervo.

Mantilla, Luis Carlos. 1986. Cali y su convento de San Francisco: documentos inéditos: homenaje de los franciscanos de Colombia a Cali en sus 450 años. Bogotá: Editorial Kelly.

Mantilla, Luis Carlos. 1995. Larrea, Fray Fernando De Jesús. Bogotá: Banco de la República. Biblioteca Virtual Biblioteca Luis Ángel Arango.

Mantilla, Luis Carlos. 2000a. Los franciscanos en Colombia. Tomo III (1700-1830). Vol. 1. Bogotá: Ediciones de la Universidad de San Buenaventura.

Mantilla, Luis Carlos. 2000b. Los franciscanos en Colombia. Tomo III (1700-1830). Vol. 2. Bogotá: Ediciones de la Universidad de San Buenaventura.

Marín Silva, Pedro. 1993. Etnolingüística e historiografía de la región de los ríos Putumayo, Caquetá y Caguán. Maguare 81. 80-104.

Moreno Gallego, Valentín. 2009. La Real Biblioteca y sus fondos americanistas: guía de fuentes. Lope de Barrientos Seminario de Cultura 2. 105-140.

Muysken, Pieter. 1999. Fuentes misioneras del quichua ecuatoriano: evidencia para su desarrollo histórico. En Sabine Dedenhach-Salazar y Lindsey Crickmay (eds.), La lengua de la cristianización en Latinoamérica: catequización e instrucción en lenguas amerindias. 
The language of christianisation in Latin America: catechisation and instruction in amerindian languages, 89-114. Bonn: Anton Saurwein Verlag (Bonner Amerikanistische Studien 32).

Ortega Ricaurte, Carmen. 1997. Los manuscritos sobre lenguas indígenas en la Biblioteca General. Senderos (Publicación Semestral de la Biblioteca Nacional) 8(31/32). 1142-1148.

Palacios, Azucena. 2006. Cambios inducidos por contacto en el español de la sierra ecuatoriana: la simplificación de los sistemas pronominales (procesos de neutralización y elisión). Huellas del contacto. Tópicos del Seminario (número monográfico) 15. 197-230.

Palacios, Azucena. 2015. De nuevo sobre la omisión del objeto directo en el español andino ecuatoriano. Cículo de Lingüística Aplicada a la Comunicación 61. 104-130.

Petersen de Piñeros, Gabriele y Carlos Patiño Roselli. 2000. El idioma uitoto. In María Estella González Pérez y María Luisa Rodríguez de Montes (eds.), Lenguas indígenas de Colombia: Una visión descriptiva, 219-238. Bogotá: Instituto Caro y Cuervo.

Pfänder, Stephan y Azucena Palacios. 2013. Evidencialidad y validación en los pretéritos del español andino ecuatoriano. Círculo de Lingüística Aplicada a la Comunicación 54. 65-98.

RAE-ASALE, DA = Real Academia Española y Asociación de Academias de la Lengua Española. 2010. Diccionario de americanismos (DA). En línea.

RAE-ASALE, NGLE = Real Academia Española y Asociación de Academias de la Lengua Española. 2010. Nueva Gramática de la Lengua Española. Manual. Madrid: Espasa.

Rochá, Joaquín. 1905. Memorándum de viajes (Regiones amazónicas). Apendice sobre los idiomas del Caquetá, Idioma inga, Coche o idioma de los indios de Sebondo, Ceona del Putumayo, Dialecto coreguaje, Carijona. Bogotá: Casa editorial de “El Mercurio”.

Rodríguez González, Sandra Patricia. 2000. Estudios sobre la lengua koreguaje. En María Stella González de Pérez y María Luisa Rodríguez de Montes (eds.), Lenguas indígenas de Colombia: una visión perspectiva, 199-213. Bogotá: Instituto Caro y Cuervo.

Santos, Fernando y Frederica Barclay (eds.). 2015[1994]. Guía Etnográfica de la alta Amazonía. Vol. I: Mai huna, yagua, ticuna. Quito: Flasco Sede Ecuador/IFEA.

Sorensen, Arthur P. Jr. 1972[1967]. Multilingualism in the Northwest Amazon. En John B. Pride y Janet Holmes (eds.), Sociolinguistics. Selected Readings, 78-93. Middlesex: Penguin Books.

Swadesh, Morris. 1955. Towards greater accuracy in lexicostatistic dating. International Journal of American Linguistics 21. 121-137.

Thomason, Sarah Grey. 2005[2001]. Language contact. An introduction. Edimburgo: Edinbourh University Press.

Toscano Mateus, Humberto. 1953. El español en el Ecuador. Madrid: C.S.I.C. (Revista de Filología Española, anejo LXI).

Tovar, Antonio. 1961. Catálogo de las lenguas de América del Sur. Buenos Aires: Editorial Sudamericana.

Tovar, Antonio y Consuelo Larrucea de Tovar. 1984. Catálogo de las lenguas de América del Sur. Madrid: Gredos.

Van der Kerke, Simon. 1999. A 19th Century Christian Doctrine in the Leko Language. En Sabine Dedenhach-Salazar y Lindsey Crickmay (eds.), La lengua de la cristianización en Latinoamérica: catequización e instrucción en lenguas amerindias. The language of christianisation in Latin America: catechisation and instruction in amerindian languages, 115-151. Bonn: Anton Saurwein Verlag (Bonner Amerikanistische Studien 32). 
Vásquez de Ruiz, Beatriz. 2000. Lenguas aborígenes del sur andino de Colombia. En María Estella González Pérez y María Luisa Rodríguez de Montes (eds.), Lenguas indígenas de Colombia: Una visión descriptiva, 217-219. Bogotá: Instituto Caro y Cuervo.

Welch, Betty y Birdie West. 2000. El tucano. En María Estella González Pérez y María Luisa Rodríguez de Montes (eds.), Las lenguas indígenas de Colombia. Una visión descriptiva, 419-436. Bogotá: Instituto Caro y Cuervo.

Wheeler, Alva L. 1970. Grammar of the siona language, Colombia, South America. University of California.

Wheeler, Alva L. 1992. Comparaciones lingüísticas en el grupo tucano occidental. En Janet Barnes, Alva Wheeler, Margaret Wheeler, Stephen H. Levinsohn, Estudios comparativos: prototucano, 17-53. Bogotá: Editorial Alberto Lleras Camargo.

Wheeler, Alva L. 2000. La lengua siona. En María Estella González Pérez y María Luisa Rodríguez de Montes (eds.), Las lenguas indígenas de Colombia. Una visión descriptiva, 181-198. Bogotá: Instituto Caro y Cuervo.

Wise, Mary Ruth (ed.). 1983. Diccionario uitoto murui. Vol. I. Yarinacocha, Pucallpa: Instituto Lingüístico de Verano.

Zwartjes, Otto, 2016. Colonial Missionaries' Translation Concepts and Practices: Semantics and Grammar. En Sabine Dedenbach-Salazar Sáenz (ed.), La transmisión de conceptos cristianos a las lenguas amerindias. Estudios sobre textos y contextos de la época colonial, 43-76. Bonn: Academia Verlag Sankt Augustin.

Zawadzky, Alfonso. 1947. Viajes misioneros del R.P.Fr. Fernando de Jesús Larrea, franciscano, 1700-1773. Cali: Impresora Bolivariana. 
